\title{
Desempeño laboral de los docentes de la Institución Universitaria ITSA
}

https://doi.org/10.21158/01208160.n87.2019.2452

Fecha de recepción: 02 de febrero de 2019

Fecha de aprobación: 18 de octubre de 2019
Karina Patricia Rodríguez-Marulanda ${ }^{1}$ Institución Universitaria ITSA kpmarulanda@gmail.com

Jorge Isaac Lechuga-Cardozo ${ }^{2}$

Universidad Autónoma de Nuevo León jorge.lechugacrd@uanl.edu.mx

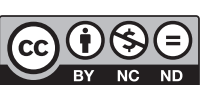

Cómo citar este artículo / To reference this article / Comment citer cet article / Para citar este artigo:

Cómo citar este artículo: Rodríguez-Marulanda, K. P.; Lechuga-Cardozo, P. (2019). Desempeño laboral de los docentes de la Institución Universitaria ITSA. Revista Escuela de Administración de Negocios, (87), 79-101.DOI: https://doi.org/10.21158/01208160. n87.2019.2452

\section{Resumen}

El estudio se propuso mostrar evidencia de los factores y los niveles de desempeño laboral de los docentes de la Institución Universitaria ITSA. Se enmarcó en una metodología positivista, con un tipo de investigación descriptiva y un diseño de campo no experimental y transeccional. Se diseñó un instrumento de 26 ítems con una versión de escala tipo Likert, y se aplicó a una muestra de 79 docentes y cinco directivos docentes, para un total de 84 sujetos. Si bien se encontró que los factores de desempeño son frecuentes y los niveles de desempeño son destacados en los directivos docentes, no son tan frecuentes y destacados en los docentes. Se identificó como problema una debilidad en el desempeño laboral generada por la falta de comunicación interna, lo cual genera inconformidades en el cuerpo docente y se explica por un proceso fallido de retroalimentación. Por lo tanto, se concluye que, a fin de aumentar la frecuencia en los factores de desempeño docente y alcanzar niveles más altos de este en los docentes, se requiere de una mayor motivación, teniendo en cuenta la importancia de la comunicación organizacional en tanto que se presenta como el mecanismo propicio para crear un clima organizacional óptimo.

Palabras clave: desempeño laboral; clima organizacional; comunicación organizacional; desempeño docente; motivación laboral; comunicación interna.

\footnotetext{
${ }^{1}$ Magíster en Gerencia educativa por la Universidad de Zulia, Venezuela. Licenciada en educación con énfasis en Humanidades y Lengua Castellana, de la Universidad del Atlántico, Colombia. ORCID: https://orcid.org/0000-0002-4726-632X

${ }^{2}$ Doctorando en Relaciones Internacionales, Negocios y Diplomacia, Universidad Autónoma de Nuevo León (Monterrey, México). Magíster en Administración de Organizaciones, Universidad Nacional Abierta y a Distancia (UNAD). Especialista en Gerencia de Negocios Internacionales, Universidad Santo Tomás Administrador de Empresas, Universidad del Norte. ORCID: https://orcid. org/0000-0002-4726-632X
} 


\title{
Work performance of teachers at ITSA University Institution
}

\begin{abstract}
The aim of this study is to show evidence of the work performance factors and work performance levels of teachers at ITSA University Institution. It was framed within a positivist methodology, with a descriptive research nature, and a non-experimental and transectional field design. A 26- item instrument was designed with a Likert-type scale version, and applied to a sample of 79 teachers and five school principals, for a total of 84 subjects. Although it was found that the performance factors are frequent and the performance levels are outstanding in school principals, they are not as frequent and outstanding in teachers. One of the problems identified is the weakness in work performance generated by a lack of internal communication, which causes dissatisfaction in the teaching staff and is explained by a failed feedback process. Therefore, it can be concluded that, in order to increase the frequency of teacher work performance factors and to achieve higher levels of teacher work performance, greater motivation is required, taking into account the importance of organizational communication as the mechanism for creating an optimal organizational climate.
\end{abstract}

Keywords: work performance; organizational climate; organizational communication; teacher performance; work motivation; internal communication.

\section{Desempenho no trabalho dos professores da Instituição Universitária ITSA}

\section{Resumo}

O estudo teve como objetivo mostrar evidências dos fatores e níveis de desempenho no trabalho dos professores da Instituição Universitária ITSA. Foi enquadrado em uma metodologia positivista, com um tipo de pesquisa descritiva e um desenho de campo não experimental e transecional. Um instrumento de 26 itens foi projetado com uma versão do tipo Likert foi aplicado a uma amostra de 79 professores e cinco gerentes de ensino, num total de 84 participantes. Embora tenha sido constatado que os fatores de desempenho são frequentes e os níveis de desempenho são excelentes nos gerentes de ensino, eles não são tão frequentes e destacados nos professores. Uma fraqueza no desempenho do trabalho gerada pela falta de comunicação interna foi identificada como um problema, o que gera discordâncias no corpo docente e é explicado por um processo de feedback fracassado. Conclui-se, portanto, que, para aumentar a frequência dos fatores de desempenho dos professores e atingir níveis mais elevados nos professores, é necessária uma maior motivação, levando em consideração a importância da comunicação organizacional que se apresenta como o mecanismo propício para criar um clima organizacional ideal.

Palavras-chave: desempenho laboral; clima organizacional; comunicaçao organizacional; desempenho docente; motivação para o trabalho; comunicação interna. 


\section{Mesure du travail des enseignants de l'université ITSA}

\section{Résumé}

L'étude vise à mettre en évidence les niveaux et facteurs de performance professionnelle des enseignants de l'université ITSA. L'investigation utilise une méthodologie positiviste, descriptive, de conception empirique non expérimentale et transectionnelle. Un instrument de type Likert, composé de 26 éléments, a été conçu et utilisé sur un échantillon de 79 enseignants et cinq directeurs pédagogiques. Les niveaux de performance sont importants chez ces derniers, mais diminuent chez les enseignants. Cela peut s'expliquer par le manque de communication interne identifié comme problématique et générant des désaccords au sein du personnel enseignant mettant en échec le processus de rétroaction. En conclusion, pour améliorer la fréquence des facteurs de performance des enseignants et atteindre des niveaux plus élevés, il est nécessaire d'améliorer leur motivation et la communication organisationnelle qui sont les mécanismes propices à la création d'un climat de travail optimal.

Mots clés: performance au travail; climat organisationnel; communication organisationnelle; performances pédagogiques; motivation au travail; communication interne. 


\section{Introducción}

G n Colombia, el desempeño laboral constituye, Cde acuerdo con Newstrom (2007), un «proceso permanente en el que se aclara y comunica a los empleados las expectativas de desempeño, y luego se les ofrece coaching y retroalimentación para asegurar las acciones deseadas $\gg$.

En el presente artículo se revisa un caso en el que se evidencia cómo, en la Institución Universitaria ITSA, se desempeñan laboralmente en la actualidad los docentes y los directivos docentes. Estos aportes teóricos facilitan la explicación del desempeño laboral.

Así mismo, en este estudio se identifica como problema una debilidad en el desempeño laboral generada por la falta de comunicación interna, lo cual genera inconformidades en el cuerpo docente y se explica por un proceso fallido de retroalimentación. En este sentido, se plantea como pregunta problema la siguiente: ¿Cuáles son los factores y los niveles de desempeño laboral de los docentes de la Institución Universitaria ITSA?
De este modo, el objetivo del artículo es presentar evidencia de los factores y los niveles de desempeño laboral de los docentes de la Institución Universitaria ITSA. Así, entonces, se realiza un estudio univariado en el que se identifica como variable el desempeño laboral. A partir de una investigación de enfoque cuantitativo, mediante la técnica de la encuesta, la investigación corresponde a un diseño no experimental, de corte trasversal o seccional, y alcanza un nivel descriptivo en el espacio geográfico de Soledad, Colombia.

En cuanto a la estructura del artículo, se presenta de la siguiente manera. Una vez se desarrolla el marco teórico, se expone la metodología utilizada para la presente propuesta. Después, se presentan factores y niveles del desempeño laboral, así como de desempeño laboral de docentes de la Institución Universitaria ITSA a partir de análisis de la información recolectada. Finalmente, se llega al planteamiento de la discusión y a la exposición de las conclusiones.

\section{Marco teórico}

A continuación, se define la variable «desempeño laboral» y sus dimensiones: factores del desempeño laboral y niveles del desempeño laboral. Lo anterior a partir de la revisión de los principales autores consultados que han trabajado sobre el tema.

\subsection{Desempeño laboral}

Al analizar la definición de desempeño laboral se encuentra que Morales y Velandia (1999) lo conceptualiza como la actuación de las personas cuando estas aplican sus aptitudes, inclinaciones y necesidades en función de los objetivos de la empresa, sitio de estudio, hogar o, en general, la sociedad la que se desenvuelven, con el propósito de obtener un resultado específico.

Matas (2006) afirma que el desempeño se refiere a la efectividad, de acuerdo con criterios sistémicos, por lo cual se mide en función de la capacidad de la administración para adaptarse, mantenerse y crecer, así como con el fin de renovarse de manera constante o, mejor aún, convertirse en una organización que aprende e incide en los fenómenos de supervivencia, adaptación y crecimiento.

Coincide con lo antes señalado el término desempeño, según Matas (2006), pues alude a una serie de comportamientos dirigidos hacia una meta 
o un resultado. El desempeño en las personas es como la combinación de sus comportamientos con sus resultados. Estos planteamientos indican que al modificar cualquier comportamiento se transforma también el desempeño, pues este alude a la conducta del personal. Así, desde la perspectiva de este autor, el desempeño se refiere al rendimiento de un conjunto de individuos en función de unas metas específicas.

Según Chiavenato (2007, p. 236), «el desempeño laboral comprende el cumplimiento del empleado conforme a los requisitos de su trabajo, demostrando sus habilidades en el ejercicio de su cargo, acorde con los objetivos de las organizaciones». En el mismo orden de ideas, Dessler (2007) lo define como el grado de cumplimiento de todas las tareas o decisiones de los empleados de una organización o empresa, con miras establecidas por esta. Por tanto, el desempeño laboral es una variable que se encuentra en función de los resultados obtenidos en la realización de las funciones inherentes al cargo. De esta manera, es posible decir que es importante estudiar el desempeño en el ámbito laboral, para lo cual es necesario que este se evalúe de manera objetiva y precisa.

Por consiguiente, se evidencia que los autores citados coinciden en su totalidad al considerar el desempeño laboral como el rendimiento o la actuación que muestra cada trabajador en su puesto laboral, en consideración y en función de las actividades que cumple, de las metas y los resultados que debe alcanzar y de su potencial de desarrollo, así como, en especial, en consideración a su contribución a la organización.

Se puede afirmar, entonces, que, para efectos de este estudio, se considera el desempeño desde la perspectiva de Chiavenato (2007), pues se entiende como la actuación del personal, en la medida en que interesa medir los factores que lo afectan y el nivel alcanzado dentro de la organización. Por consiguiente, en una sociedad moderna, en la que siempre se ha medido el valor de las personas por el desempeño en su trabajo, el desempeño se considera necesario para una gestión eficaz y acorde con las exigencias de la organización, según lo que se establece en el plan estratégico orientado al cumplimiento de las metas.

\subsection{Factores del desempeño laboral}

Los factores laborales se refieren a las condiciones de las organizaciones que repercuten de manera directa sobre el desempeño de sus trabajadores. $\mathrm{Al}$ respecto, Cabrera y Toro (1985), en su teoría sobre la conceptualización de los elementos conductuales de la acción, configuran el desempeño como un efecto de la interacción de cuatro elementos: contexto, tiempo, acción y la meta o resultado. El contexto viene a ser el conjunto de las circunstancias internas - individuales - y externas que anteceden y acompañan la acción; el tiempo es la época, el periodo o el momento específico; la acción es la ejecución de una actividad específica; y la meta o el resultado es el efecto o el producto de la acción.

Estos autores hacen referencia a que los elementos mencionados conforman el denominado «desempeño general $\gg$, de modo que se define este como una acción o un conjunto de resultados que tienen lugar en un momento determinado y está condicionado por un conjunto de factores que conforman un contexto de las organizaciones.

Por su parte, Matas (2006) plantea que, aplicado a la administración pública, los factores del desempeño laboral se relacionan con el uso racional de los recursos materiales y financieros, por cuanto la eficiencia se demanda en los niveles operativos. En el desempeño laboral de las instituciones públicas resalta el factor humano centrado en la coordinación entre el nivel operativo y el estratégico de las organizaciones.

En este sentido, Chiavenato (2007, p. 244) señala: «Cada trabajador conoce su nivel de desempeño dado que cuenta con la información necesaria». Por lo general, en las organizaciones los trabajadores realizan ciertas funciones que les generan recompensas, remuneración, seguridad y estatus, y de modo recíproco el empleado responde con el trabajo y el desempeño de sus tareas. Este autor 
coincide en algunos de sus planteamientos con Robbins (2008) al exponer la existencia de factores a través de los cuales se mide el desempeño laboral.

Cuando se habla de factores que miden el desempeño laboral se hace referencia a una serie de condiciones que determinan la eficiencia en el puesto de trabajo, las cuales varían entre una profesión y otra. En el caso específico de la función directiva de los centros escolares, los factores que miden el desempeño están relacionados con la capacidad de gerenciar los planteles, mantener la calidad educativa y establecer relaciones de solidaridad y cooperación con las instituciones y las comunidades que rodean la escuela.

A continuación, se presentan los diferentes factores del desempeño laboral que presentan Robbins (2008) y Matas (2006), entre otros, los cuales son: conocimiento del trabajo, producción, responsabilidad y capacidad de liderazgo.

\subsubsection{Conocimiento del trabajo.}

$\mathrm{Al}$ analizar el conocimiento del trabajo, Maristany (2003) asevera que se trata de la medida en la cual el trabajador conoce los procedimientos y las técnicas que conforman el trabajo que desempeña, así como de la capacidad de llevarlos a la práctica apoyados en el manejo del conocimiento adquirido en su desarrollo. Por su parte, Koontz y Weirich (2007) plantean que el conocimiento del trabajo está determinado por la competencia humana general, la cual es el producto del dominio de conceptos, destrezas y actitudes; ser competente significa que la persona tiene el conocimiento declarativo - la información y los conceptos-, es decir, sabe lo que hace, por qué lo hace y conoce el objeto sobre el que actúa.

Para Robbins (2008), ser competente implica tener la capacidad de ejecución, es decir, el conocimiento procesal o las destrezas intelectuales y psicomotoras para, en efecto, llevar a cabo la ejecución sobre el objeto. Finalmente, ser competente implica tener la actitud o el conocimiento actitudinal orientado a querer hacer uso del conocimiento declarativo y procesal, además de actuar de una manera que se considera correcta. Por tanto, se evidencia que los autores citados abordan el conocimiento del trabajo como un factor en el desempeño laboral, y denotan así cómo su manejo derivará en una actuación específica del personal, por cuanto le adjudica el manejo de las actividades encomendadas en la organización con las competencias necesarias en el ámbito teórico.

\subsubsection{Producción.}

De acuerdo con el criterio de Maristany (2003), la producción en el trabajo se expresa en el balance entre la cantidad y la calidad de trabajo. La cantidad de trabajo comprende la medida en que se produce trabajo, supone un nivel de actividad o esfuerzo que necesita un operador humano para cumplir las exigencias o los criterios laborales. Esta cantidad de trabajo debe estar en correspondencia con la calidad obtenida, por lo cual, a fin de lograr un adecuado desempeño, deben ponderarse ambos factores.

Según el criterio de Koontz y Weirich (2007), la calidad laboral afecta de manera positiva la rentabilidad de las organizaciones, por lo que es necesario apostar por la introducción de dichas medidas en la gestión empresarial. La calidad del trabajo en cualquier empresa se sustenta en la capacidad de mantener la operación estable de sus sistemas. Además, a fin de lograrlo, se necesita contar con personas motivadas y capacitadas para desarrollar un buen trabajo. Cuando las personas actúan de forma consistente y están dispuestas a superarse de manera constante, sumados los recursos necesarios, se puede ser competitivo en cualquier ámbito.

En este sentido, Chiavenato (2007) señala que la cantidad de trabajo que el empleado es capaz de realizar en un tiempo determinando determina el nivel de compromiso y las capacidades de administración del tiempo. La calidad de trabajo se refiere al esmero con el que un empleado realiza su trabajo. Una gestión eficaz de los recursos humanos es, entonces, indisociable con la calidad laboral. Por tanto, los responsables de las empresas tendrían que empezar por usar la calidad laboral como un factor productivo. Uno de los aspectos más 
importantes y básicos para que una organización pueda alcanzar un nivel de competitividad es tener la capacidad de obtener una integración eficiente de las personas que en ella laboran con los recursos físicos y materiales necesarios.

\subsubsection{Responsabilidad.}

En cuanto a la responsabilidad como factor laboral, según Maristany (2003), es la medida en la que se asume la responsabilidad de un puesto. La responsabilidad ante el trabajo es la respuesta positiva ante la obligación contraída, actitud que se asume ante los resultados de la labor. Implica que sabe responder ante los demás por una actividad encomendada.

Koontzy Weirich (2007, p. 56) postulan lo siguiente: «la responsabilidad es la obligación que los supervisados les deben a sus superiores con respecto al ejercicio de la autoridad que le fue delegada como una forma para lograr los resultados esperados». El autor se refiere a la manera como el empleado se dedica al trabajo y ejecuta el servicio dentro del plazo estipulado. La considera, además, un estado en el que se asume la vigilancia necesaria para obtener los resultados deseados.

En este sentido, estos autores agregan que, en la mayoría de las organizaciones, el departamento de recursos humanos es responsable de los trabajos que realiza su personal. Sin embargo, es esencial que los gerentes tengan un papel clave de principio a fin, de manera que quienes tendrán la responsabilidad de llevar a cabo evaluaciones participen de manera directa en los programas y así se alcancen el éxito y los objetivos propuestos.

De acuerdo con Díaz (2005), la responsabilidad es la habilidad del ser humano para medir y reconocer las consecuencias de un episodio que se llevó a cabo con plena conciencia y libertad. Por tanto, una persona responsable es aquella que desarrolla una acción de forma consciente y que puede ser imputada por las derivaciones que dicho comportamiento posea. De este modo, la responsabilidad es una virtud presente en todo hombre que goce de su libertad.
En este mismo sentido se expresa Chiavenato (2007), quien afirma que la responsabilidad se consolida cuando en un colectivo los trabajadores y los dirigentes se relacionan de forma constante, analizan los problemas desde todos los ángulos con el propósito de concebir el proceso de trabajo como algo social, así como personal, a fin de fomentar la responsabilidad por las acciones en la empresa. Sobre esta base se establece que la responsabilidad de las empresas implica - en especial de las que prestan servicio público, como lo es, por ejemplo, el Banco Central de Venezuela, subsede Maracaibo-, una seria consideración del pacto de sus acciones en la sociedad. De igual forma, la sensibilidad del establecimiento frente a una relación entre las operaciones y su política.

De esta manera, esto se podría entender de formas más exactas al determinar que una persona caracterizada por su responsabilidad es aquella que tiene la virtud no solo de tomar una serie de decisiones de manera consciente, sino también de asumir las consecuencias que tengan estas decisiones y de responder por ellas ante quien corresponda en cada momento.

\subsubsection{Capacidad de liderazgo.}

Kotter (2005, p. 26) indica que el liderazgo consiste «en el proceso de conducción que implica ejercer la dirección organizacional, con iniciativa y principalmente utilizando medios no coercitivos $\gg$. Por tanto, se entiende que el liderazgo comprende cualquier intento expresado y dirigido a impactar la conducta de otras personas. Desde el punto de vista de los postulados de Koontz y Weirich (2007, p. 145), el liderazgo «es el arte o proceso de influir en las personas para que contribuyan voluntaria y entusiastamente al cumplimiento de metas grupales $\gg$.

En este sentido, las personas que ejercitan el liderazgo en las organizaciones deben desarrollar rápidamente las capacidades y las actitudes imprescindibles para impulsar el desarrollo de la institución a mediano y largo plazo. Sin embargo, ¿cómo desarrollar esas capacidades en un líder si no son parte de sus características personales? Esto podría sonar utópico, pero con el adecuado conocimiento es lograble. 
Por su parte, Chiavenato (2007, p. 406) expone que ese tipo de liderazgo «posee autenticidad, el líder es aquella persona capaz de provocar la liberación, desde dentro de la energía interior de otros seres humanos que se han propuesto para lograr su propia dignificación y la de aquellos con quienes conviven». El liderazgo es la función que ocupa una persona que se distingue del resto y es capaz de tomar decisiones acertadas para el grupo, equipo u organización que preceda, de modo tal que inspira al resto de los que participan de ese grupo a alcanzar una meta común. Por esta razón, se dice que el liderazgo implica a más de una persona, quien dirige - el líder- y aquellos que lo apoyen — los subordinados - y permitan que desarrolle su posición de forma eficiente.

Con relación a este punto destacan, en primera instancia, las consideraciones de Robbins y Coulter (2005, p. 422), quienes definen que la capacidad de liderazgo es «como un proceso que se basa en influir en un grupo para orientarlo hacia el logro de objetivos». Este principio se sustenta en la teoría de las relaciones humanas, en la que se plantea un entramado de poder, jerarquía y dominación, por medio del cual, en todo grupo u organización, existe una gran mayoría que asumen el rol de seguidores y uno o varios que se presentan como líderes o conductores de esas masas hacia las metas preestablecidas.

Cabe destacar que el planteamiento de Ginebra (2008) coincide con los resultados cuando expresa que el liderazgo se relaciona con la conducción, la dirección y el mando, de manera que representa más una responsabilidad que un rango de privilegio en las organizaciones. De acuerdo con los planteamientos de los autores citados, se establece una potencialidad liberadora, lo cual convierte al líder en el servidor de sus seguidores, en cuanto asume la misión fundamental de ayudarlos a superar los obstáculos para que sean capaces de poner en acción su total capacidad al servicio de la consecución de los objetivos propios y compartidos con su grupo.

\subsubsection{Identidad laboral.}

Según el criterio de Koontz y Weirich (2007), la identidad organizacional define el grado en el cual el trabajador se siente identificado con las metas y los objetivos trazados por la organización o institución, y en función de esto orienta y organiza su comportamiento al logro de estos, ejecutando una labor eficiente y eficaz en sus actividades de trabajo.

De igual forma, Chiavenato (2007) sostiene que la identidad laboral se expresa en la medida en que el trabajador siente reciprocidad con los lineamientos laborales de la organización y se orienta a lograr la misión y la visión al identificarse con estas. Dicha identidad lo impulsa a realizar una labor ajustada a los propósitos establecidos y a alcanzar metas de excelencia.

La identidad laboral, de acuerdo con Robbins (2008, p. 34), se refiere a «la congruencia de las necesidades $\mathrm{u}$ objetivos individuales con las metas o necesidades de la organización». Sostiene el autor que cuando ambas son específicas y retadoras llevan a un alto desempeño, lo cual involucra la colaboración, la proactividad y la perseverancia en la consecución de los logros o éxitos.

De esta forma, Díaz (2005) plantea que un sujeto puede interactuar en múltiples nosotros, de manera que es uno de los más importantes el que se vincula con el mundo laboral. Desde la sociología del trabajo se define la identidad laboral como la idea de un yo único y de un nosotros que se construye en los espacios laborales. También se busca enmarcar las experiencias comunes en el interior de la división del trabajo, lo que posibilita la definición de grupos relativamente homogéneos para sí mismos y los otros grupos laborales y sociales.

Al respecto, se puede señalar que el trabajador como tal debe manifestar, a través de su desempeño, la identidad laboral mediante su actuación como colaborador proactivo y perseverante en la ejecución de sus actividades. De acuerdo con el planteamiento desarrollado, se establece que la identidad laboral es un factor que guarda estrecha relación con la cultura organizacional, pues la actitud de colaboración e integración voluntaria de sus miembros se profundiza cuando en el entorno aparecen condiciones que garanticen al trabajador su estabilidad tanto laboral 
como física y emocional, lo que les genera la oportunidad de ser creativos e innovadores $y$, como consecuencia, se evidencia un máximo desempeño.

\subsection{Niveles del desempeño laboral}

En cuanto al tema, el nivel de desempeño laboral se relaciona con la actitud de los trabajadores frente a las responsabilidades, las acciones y las tareas diarias; también con el nivel de satisfacción de las expectativas que se tenga sobre la actividad desarrollada y la recompensa que se percibe como consecuencia de un resultado esperado.

Chiavenato (2007) refiere que un buen desempeño debe contener un nivel adecuado en los factores que determinan la actuación. Matas (2006) afirma que el nivel de desempeño laboral se relaciona con la responsabilidad de la gestión pública ligada a los procesos de democratización que se relaciona con la actuación de la gente y lo ejerce a través del funcionario, lo que determina así un nivel de actuación frente a las exigencias del aparato de las administraciones públicas.

Al respecto, Tobón (2004, p. 76) define el nivel de desempeño laboral como «un conjunto de roles que ejecuta el educador en el trabajo educativo con sus alumnos». Para los efectos de la educación media general, este actúa como un promotor de experiencias significativas con capacidad para utilizar estrategias y recursos que produzcan en el dicente el desarrollo de la creatividad, la participación activa en su aprendizaje constructivista $y$, por ende, emancipador, de manera que se da una adecuada transferencia de conocimientos, habilidades cognitivas y destrezas a situaciones de la vida real y el desarrollo de actitudes y valores.

De igual manera, señala que el desempeño laboral en las organizaciones es el resultado de la combinación de dos aspectos claves: primero, la excelencia de una organización, la que a su vez refleja la calidad de acción de sus individuos; y el segundo, reflejado en el conocimiento y la composición de ese proceso por parte de sus entes involucrados.
Por tanto, el nivel de desempeño laboral debe comenzar por el gerente, quien es el líder de su institución y planifica, dirige, organiza, maneja y establece un adecuado clima organizacional, a fin de lograr y conseguir la satisfacción laboral con los objetivos planificados. Tanto los coordinadores de áreas como el directivo son guías y deben ser capaces de adquirir nuevas misiones para motivar a los empleados en la aplicación de nuevas estrategias de capacitación por las que se promueve el cambio, de modo que logren así tomar el papel que les corresponda.

Al respecto, Blanco y Di Vora (2000, p. 68) establecen cuatro grados o niveles de desempeño laboral: «Destacado, competente, básico e insatisfactorio». Estos constituyen respuestas reconocibles y evaluables ante las preguntas: ¿cuán bien se debe hacer?, o ¿cuán bien se está haciendo? A continuación, se explican estos niveles según los autores.

\subsubsection{Destacado.}

De acuerdo con lo planteado por Blanco y Di Vora (2000), este nivel explica la exigencia de tal manera que presenta esmero en el trabajo y logra así una altísima calidad, al tiempo que manifiesta conocer el trabajo y demuestra experiencia en las funciones de facilitador, orientador, investigador, promotor social, evaluador y planificador. Además, este nivel demuestra un excelente espíritu de colaboración en las relaciones interpersonales con los compañeros.

Así mismo, contribuye a formar y afianzar valores $y$ actitudes mientras desarrolla en cada alumno sus capacidades de aprendizaje relacionadas con el saber, el hacer y el convivir. Otro aspecto relevante en este nivel es que desarrolla en los trabajadores los intereses, las aptitudes y los estilos de aprendizaje. Además, estimula el espíritu de investigación en la búsqueda del conocimiento, así como motiva el desarrollo de la creatividad en busca de experimentar con innovaciones en las diferentes tareas que conforman el puesto de trabajo.

De acuerdo con Tobón (2004), existen múltiples y variadas aproximaciones conceptuales al hecho 
de ser destacado laboralmente. Un concepto por lo general aceptado la define como una capacidad efectiva para llevar a cabo de forma exitosa una actividad laboral plenamente identificada. De esta forma, destacarse no es una probabilidad de éxito en la ejecución de un trabajo, es una capacidad real y demostrada.

En este sentido, una buena categorización de ser destacado a nivel laboral es la que permite aproximarse mejor a tres enfoques generales. El primero lo concibe como la capacidad de ejecutar las tareas; el segundo la concentra en atributos personales —actitudes, capacidades-, y el tercero, denominado «holístico», incluye a los dos anteriores.

En el mismo orden de ideas, Díaz (2005) plantea que es la capacidad integral que tiene una persona para desempeñarse eficazmente en situaciones específicas de trabajo. También se relaciona con el correcto desempeño y con la competencia profesional de quien dispone de los conocimientos, las destrezas y las aptitudes necesarios para ejercer una profesión, puede resolver los problemas profesionales de forma autónoma y flexible, y está capacitado para colaborar en su entorno profesional y en la organización del trabajo. Estas competencias son útiles para el desempeño productivo en una situación real de trabajo y se obtienen no solo a través de la instrucción, sino también - y en gran medida - mediante el aprendizaje por experiencia en situaciones concretas de trabajo.

Sobre la base de lo expuesto puede decirse que en este nivel de desempeño laboral es en el que el trabajador podrá ser capaz de demostrar un amplio conocimiento del contenido de las disciplinas que ejecuta y establecer conexiones entre estos y otros aspectos de la realidad, de manera tal que evidencie una actualización permanente de estos.

\subsubsection{Competente.}

De acuerdo con Blanco y Di Vora (2000, p. 69), en este nivel se demuestra interés en colaborar con el trabajo, así como unas adecuadas relaciones interpersonales, sin llegar a ser excelentes: «es capaz de ejecutar los roles demostrando moderados conocimientos, con lo cual establece las relaciones interpersonales necesarias $\gg . \mathrm{Al}$ analizar este planteamiento, se establece que para alcanzar un nivel de desempeño competente es necesario la existencia de una adecuada cultura, es decir, que esté orientada hacia las personas, sin dejar de lado el cumplimiento de las metas y los objetivos establecidos, de tal manera que se puedan cubrir las expectativas de sus miembros, y estos a su vez cumplirán los objetivos de la empresa. Este propósito se logra cuando la organización establece programas de desarrollo del capital humano en función de las brechas observadas.

Para Díaz (2005), ser competente en el desempeño laboral es la capacidad de responder exitosamente una demanda compleja o llevar a cabo una actividad o tarea, según criterios de desempeño definidos por la organización o el sector. El personal competente abarca los conocimientos - saber-, actitudes saber ser- y habilidades — saber hacer- de un individuo. Las competencias regularmente incluyen competencias técnicas, las cuales son aquellas requeridas para desempeñar las actividades que componen una función laboral según los estándares y la calidad establecidos por la empresa o por el sector productivo correspondiente.

Según Tobón (2004), es una metodología que busca identificar las actividades y las funciones que deben realizar las personas de una organización a fin de lograr los objetivos organizacionales. Se inicia al establecer, en reuniones de trabajo con especialistas de los procesos comprendidos, el propósito principal del sector, la organización o la función productiva analizados, y luego se desagregan de forma sucesiva las funciones y las subfunciones hasta encontrar las actividades realizables por una sola persona. Ser competente se puede concebir de manera colectiva o de forma individual, pues se centra en los resultados que el trabajador o la organización deben lograr y no en el proceso que se sigue para obtenerlos, de modo que es esta su principal diferencia con el análisis ocupacional de las tareas. 
Por tanto, ser competente a nivel de desempeño laboral es un proceso que tiene como fin determinar si una persona es competente o aún no lo es para realizar una función productiva o de servicio determinada, de acuerdo con una metodología predefinida que incluye distintas etapas de recopilación de información sobre el desempeño real del evaluado en su contexto laboral. La evaluación se basa en criterios específicos que están definidos en un conjunto de estándares de competencia laboral validados por el mundo productivo.

\subsubsection{Básico.}

Para Blanco y Di Vora (2000), en este nivel se demuestra una calidad mínima necesaria y el trabajador conoce solo lo suficiente sobre las tareas o funciones que debe realizar. Demuestra conocimiento básico acerca del contenido de las disciplinas pero no puede realizar conexiones con otros aspectos de la disciplina o relacionarlo con la realidad.

Según Tobón (2004), el nivel de desempeño laboral básico es aquel que se desarrolla, principalmente, en el inicio del desempeño de las labores y comprende aquellos conocimientos y habilidades que permiten progresar en el ciclo laboral y social. Tradicionalmente, se incluyen entre las competencias básicas para ejercer una labor la aplicación de recursos, la solución de problemas, la interacción con otros y el manejo creciente de tecnologías de la información.

En el análisis de los postulados expuestos sobre el desempeño básico se encuentra que los trabajadores son capaces de cumplir con sus tareas y generan algún valor agregado al proceso, pero no lo suficiente como para proyectarse sobre otros aspectos que, de una u otra forma, se relacionan con el cargo. De esta manera, se establece un nivel conformista en el que el principal objetivo es cumplir sin medir el impacto positivo o negativo de las acciones.

$\mathrm{Al}$ respecto, Díaz (2005) señala que el desempeño laboral, en un nivel básico, se utiliza con el fin de calificar lo que resulta esencial en algo o que constituye su base. Lo básico es lo elemental o lo primordial. Muchas veces se utiliza la concepción para establecer distinciones entre categorías, niveles o servicios. El término desempeño básico presenta dos usos en el lenguaje corriente de nuestro idioma. Por una parte, implica el libramiento de condiciones básicas de trabajo y, por otra, el desempeño implica el cumplimiento efectivo de las actividades y funciones inherentes a un cargo o a un trabajo.

De esta forma, el desempeño a nivel básico son aquellas habilidades y conductas que explican desempeños medios, cumplimiento de necesidades y funciones en el mundo del trabajo y que, por lo general, se verbalizan en términos de atributos o rasgos personales, como es el caso de la orientación al logro, la proactividad, la rigurosidad, la flexibilidad y la innovación, entre otros.

\subsubsection{Insatisfactorio.}

De acuerdo con los postulados de Blanco y Di Vora (2000), en este nivel se presenta una pésima calidad en el trabajo, lo que demuestra poco conocimiento de este, de modo que siempre se improvisa, no se planifica ni organiza, tampoco se controla el proceso, además de que no se evalúan las actividades realizadas. De igual forma, estos trabajadores no colaboran con sus compañeros ni con la organización, no presentan capacidad de intuición, demuestran poseer pocas e incluso inadecuadas relaciones interpersonales, no se comunica con su jefe ni con los compañeros y no colaboran en nada.

Según Tobón (2004), lo insatisfactorio a nivel de desempeño laboral es la principal causa de problemas, incidencias, bajo rendimiento y bajas laborales. Muchos trabajadores no se encuentran cómodos en sus lugares de trabajo y esto repercute en su forma de trabajar. Este es un tema que preocupa a la mayoría de las organizaciones en la actualidad.

Para Díaz (2005), el nivel insatisfactorio es un sentimiento interior que experimenta una persona cuando siente que una realidad determinada no cumple sus expectativas. La insatisfacción muestra un nivel de desencanto personal producido por la frustración de no cumplir un deseo determinado. Esto repercute en un inadecuado desempeño laboral. 
Así mismo, la persona insatisfecha laboralmente vive más pendiente de la carencia y no practica la efectividad o el cambio. De este modo, sufre mucho porque no valora todo aquello que sí posee. Es como el niño eternamente insatisfecho. De esta manera, la insatisfacción puede ser un punto de inicio de un proceso de desarrollo personal, tal como ocurre cuando una persona inicia un proceso de coaching con el objetivo de poner fin a ese sentimiento interior y así abrir las puertas de la felicidad. Alcanzar este punto implica esfuerzo y superación.

\section{Metodología}

\subsection{Diseño}

La investigación en la que se origina este artículo se realizó desde un enfoque cuantitativo, con una metodología cuantitativa de tipo descriptiva y un diseño no experimental, transeccional y de campo. La variable trabajada - desempeño laboral- se analizó a través de la encuesta realizada a directivos y docentes de la Institución Universitaria ITSA.

El enfoque de la presente investigación es cuantitativo, ya que las técnicas que se utilizaron para la recolección de datos como, por ejemplo, la encuesta, ayudan a recopilar información y, como bien señala Hurtado (2007, p. 35), los estudios con enfoque positivista cuantitativos se definen como aquellos «basados en la observación, descripción, explicación [que]reducen la realidad a los aspectos cuantificables, los mismos se centran en la búsqueda de respuestas de manera objetiva». Al respecto, Hernández, Fernández y Baptista (2014, p. 14) señalan que la teoría de la ciencia por la cual se sostiene el paradigma positivista se caracteriza por «afirmar que el único conocimiento verdadero es aquel que es producido por la ciencia, particularmente con el empleo de su método». En consecuencia, el positivismo asume que solo las ciencias empíricas son fuente aceptable de conocimiento.

El alcance establecido es descriptivo (Tamayo y Tamayo, 2009), dado que la investigación comprende la descripción, el registro, el análisis y la interpretación de la naturaleza actual, más la posición o el proceso de los fenómenos sobre conclusiones acerca de cómo un grupo o persona conduce o funciona entre el presente. El estudio es de tipo descriptivo, ya que evidencia todas las características de las variables estudiadas.

El diseño de investigación escogido es el transversal, porque el estudio no tendrá un seguimiento en el tiempo y se efectuará en un periodo determinado (Hernández et al., 2014, p. 154). Agrega Chávez (2007, p. 89): «Los diseños transaccionales tienen como objeto indagar la incidencia de las modalidades o niveles de una o diversas variables a un grupo de personas u otros seres vivos, objetos, situaciones, contextos, fenómenos, comunidades y así proporcionar su descripción».

En cuanto al diseño no experimental, según Hernández et al. (2014, p. 205), las investigaciones con este diseño «se realizan sin la manipulación deliberada de variables y en los que solo se observan los fenómenos en su ambiente natural para después analizarlos». Por consiguiente, el estudio es de diseño no experimental, ya que en ningún momento se manipulan las variables, sino que se estudian tal como se presentan en la realidad sin afectarlas.

\subsection{Participantes}

La población de referencia considerada son los directivos y docentes de la Institución Universitaria ITSA en el municipio de Soledad, Atlántico. 
Tabla 1. Distribución de la población

\begin{tabular}{|c|c|c|c|}
\hline Institución & Directivos & Docentes & Total \\
\hline Institución Universitaria ITSA & 5 & 100 & 105 \\
\hline
\end{tabular}

Fuente. Elaboración propia.

Para el presente trabajo se seleccionaron 79 docentes y cinco directivos docentes de la Institución Universitaria ITSA. El tipo de muestreo es «no probabilístico», es decir, la muestra se seleccionó de acuerdo con la disposición de atención al libreto de entrevista en el campo. A fin de hallar la muestra se utilizó el software estadístico de STATS: 0, donde para un universo de 100 docentes, con un error estándar aceptado de $5 \%$, un porcentaje estimado de la muestra del $50 \%$ y un nivel deseado de la muestra del $95 \%$, arroja que el tamaño de la muestra es de 79. La selección de los encuestados se realiza con base en las siguientes características: ubicación geográfica y perfil de docente o directivo docente.

Tabla 2. Ficha técnica de la investigación

\begin{tabular}{|l|l|}
\hline Universo & Cien docentes y directivos docentes de la Institución Universitaria ITSA \\
\hline Ámbito & Regional Soledad (Colombia) \\
\hline Método de recogida de información & Encuesta, suministrada presencialmente \\
\hline Unidad muestral & Docente y directivo docente de la Institución Universitaria ITSA \\
\hline Tamaño de la muestra & 79 \\
\hline Muestreo & No probabilístico de conveniencia \\
\hline Trabajo de campo & Octubre del 2018 \\
\hline Número de encuestas realizadas & 79 \\
\hline Respuestas válidas & 79 \\
\hline
\end{tabular}

Fuente. Elaboración propia.

\subsection{Instrumentos}

Se diseñó un instrumento en conformidad con la variable desempeño laboral y sus dimensiones factores del desempeño laboral y niveles del desempeño laboral, el cual se aplicó a 79 docentes y cinco directivos docentes de la Institución Universitaria ITSA en Soledad, Colombia. En cuanto al instrumento, Bavaresco de Prieto (2004, p. 98) afirma que estos «conducen a la solución del problema planteado». Por tanto, se utilizó como instrumento el cuestionario cerrado. En esta investigación se creó un instrumento que se ajusta en la redacción al personal directivo, con el propósito de medir la variable desempeño laboral de la población docente, conformada por 26 profesores, de los cuales
14 están relacionados con la dimensión factores de desempeño laboral y 12 se encuentran relacionados con la dimensión niveles de desempeño laboral. Cada ítem presenta preguntas de alternativas cerradas derivadas del marco teórico de la variable en dimensiones e indicadores, las cuales se respondieron de acuerdo con las opciones de respuesta de la escala Lickert: siempre, casi siempre, algunas veces, casi nunca y nunca. En cuanto a la presentación del instrumento, se organizó de la siguiente forma: 1) identificación del investigador, 2 ) instrucciones para su llenado, 3) presentación de los ítems y sus alternativas para responderlos, y 4) cuadro de operacionalización de las variables. 


\subsection{Procedimiento}

Con el propósito de entender el problema se realiza una recopilación de fuentes secundarias, principalmente, de bases de datos, textos y artículos especializados en gestión de empresas. Una vez compilada la información se construye el artículo. Luego, se levanta la información primaria a través del uso de la técnica de la encuesta y el instrumento cuestionario estilo Likert, el cual sirve para la recolección de dicha información. De este modo, una vez se recolectó la información primaria, se tabuló la información a través de un software especializado y se expresó a través de gráficos y cuadros. Finalmente, se realizaron las recomendaciones y las conclusiones a la luz de los objetivos trazados. Concluida esta fase, se procedió a la elaboración del informe final, así como del artículo producto del trabajo realizado (Bascón, Cazallo, Lechuga y Meñaca, 2016, p. 39; Lechuga et al., 2018, p. 196).

\section{Resultados y discusión}

T as categorías analizadas fueron la variable Udesempeño laboral y sus dimensiones factores del desempeño laboral y niveles del desempeño laboral. A fin de distribuir y procesar los datos se diseñaron tablas de doble entrada en las que se plasmaron los datos proporcionados por los sujetos en atención a la sistematización de variables. Para el análisis de los datos es necesario determinar de qué forma se procesarán y bajo qué lineamientos. Según Chávez (2007), la tabulación de los datos es una técnica empleada por los investigadores con la finalidad de procesar la información recolectada, la cual permite lograr la organización de los datos relativos a una variable, indicadores e ítems. Es necesario realizar un proceso sistemático y cuidadoso con relación al traslado de las respuestas emitidas por el sujeto de la muestra a una tabla de tabulación. De igual forma, debe presentarse el análisis que se le dio a cada uno de los indicadores planteados en el estudio.
Tamayo y Tamayo (2006) define el procesamiento de los datos como las fases que permiten obtener conclusiones sobre las interrogantes del estudio y propone las siguientes fases: establecer categoría, codificarlas, tabular y llevarlas a cuadros y gráficos que permitan analizar las variables de estudio. La información se presenta en tablas de distribución frecuencial y porcentual por indicadores que permitan su análisis. Posteriormente, para la discusión de los resultados, se elaboraron tablas de distribución de medias aritméticas para los indicadores, las dimensiones y las variables. A continuación, se presentan las tablas 3, 4, 6 y 6, cada tabla con su respectivo análisis descriptivo de los instrumentos aplicados.

Para el porcentaje total se toma cada resumen, se multiplica por 100 y luego se divide por la cantidad de indicadores en múltiplos de 100; por ejemplo, cuatro indicadores se dividirían en 400, y seis indicadores se dividirían en 600 . 
Tabla 3. Dimensión: factores del desempeño laboral

\begin{tabular}{|c|c|c|c|c|c|c|c|c|c|c|c|c|c|c|c|c|c|c|c|c|}
\hline \multirow{3}{*}{$\begin{array}{c}\text { Alternativas } \\
\text { Población } \\
\text { Porcentaje } \\
\text { Indicador } \\
\end{array}$} & \multicolumn{4}{|c|}{ Siempre } & \multicolumn{4}{|c|}{ Casi siempre } & \multicolumn{4}{|c|}{ Algunas veces } & \multicolumn{4}{|c|}{ Casi nunca } & \multicolumn{4}{|c|}{ Nunca } \\
\hline & \multicolumn{2}{|c|}{ Dir } & \multicolumn{2}{|c|}{ Doc } & \multicolumn{2}{|c|}{ Dir } & \multicolumn{2}{|c|}{ Doc } & \multicolumn{2}{|c|}{ Dir } & \multicolumn{2}{|c|}{ Doc } & \multicolumn{2}{|c|}{ Dir } & \multicolumn{2}{|c|}{ Doc } & \multicolumn{2}{|c|}{ Dir } & \multicolumn{2}{|c|}{ Doc } \\
\hline & $\mathbf{F a}$ & $\%$ & $\mathbf{F a}$ & $\%$ & $\mathbf{F a}$ & $\%$ & $\mathbf{F a}$ & $\%$ & $\mathbf{F a}$ & $\%$ & $\mathbf{F a}$ & $\%$ & $\mathbf{F a}$ & $\%$ & $\mathbf{F a}$ & $\%$ & $\mathbf{F a}$ & $\%$ & $\mathbf{F a}$ & $\%$ \\
\hline $\begin{array}{c}\text { Conocimiento } \\
\text { del trabajo }\end{array}$ & 2 & 40 & 23 & 29 & 3 & 60 & 17 & 22 & 0 & 0 & 20 & 25 & 0 & 0 & 14 & 18 & 0 & 0 & 5 & 6 \\
\hline Producción & 2 & 40 & 21 & 27 & 2 & 40 & 24 & 30 & 1 & 20 & 19 & 24 & 0 & 0 & 11 & 14 & 0 & 0 & 4 & 5 \\
\hline Responsabilidad & 3 & 60 & 18 & 23 & 2 & 40 & 20 & 25 & 0 & 0 & 22 & 28 & 0 & 0 & 9 & 11 & 0 & 0 & 10 & 13 \\
\hline $\begin{array}{c}\text { Capacidad de } \\
\text { liderazgo } \\
\end{array}$ & 3 & 60 & 10 & 13 & 2 & 40 & 23 & 29 & 0 & 0 & 32 & 40 & 0 & 0 & 12 & 15 & 0 & 0 & 2 & 3 \\
\hline Identidad laboral & 2 & 40 & 8 & 10 & 1 & 20 & 6 & 8 & 1 & 20 & 12 & 15 & 0 & 0 & 22 & 28 & 1 & 20 & 31 & 39 \\
\hline Resumen & \multicolumn{2}{|c|}{240} & \multicolumn{2}{|c|}{102} & \multicolumn{2}{|c|}{200} & \multicolumn{2}{|c|}{114} & \multicolumn{2}{|c|}{40} & \multicolumn{2}{|c|}{132} & \multicolumn{2}{|c|}{$\mathbf{0}$} & \multicolumn{2}{|c|}{86} & \multicolumn{2}{|c|}{20} & \multicolumn{2}{|c|}{66} \\
\hline Porcentaje & \multicolumn{2}{|c|}{48} & \multicolumn{2}{|c|}{20} & \multicolumn{2}{|c|}{40} & \multicolumn{2}{|c|}{23} & \multicolumn{2}{|c|}{8} & \multicolumn{2}{|c|}{26} & \multicolumn{2}{|c|}{0} & \multicolumn{2}{|c|}{17} & & & & 3 \\
\hline
\end{tabular}

Nota. ${ }^{*} \mathrm{Fa}=$ frecuencia absoluta. ${ }^{*}$ Dir $=$ directivos. Doc $=$ docentes.

Fuente. Elaboración propia.

Figura 1. Factores del desempeño laboral
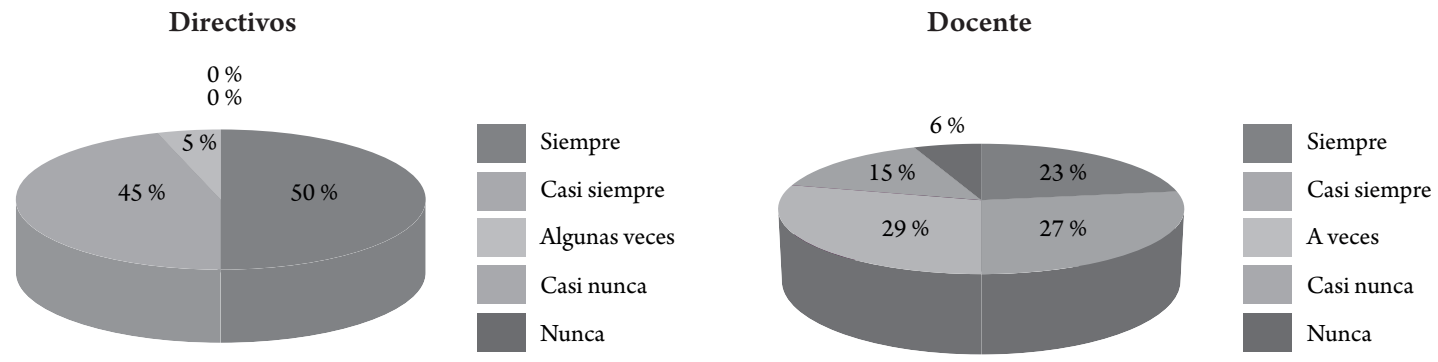

Fuente. Elaboración propia.

Luego del procesamiento de los instrumentos se procede a realizar la distribución estadística de los datos. Así, en la tabla 2 de la dimensión factores del desempeño laboral se exponen los resultados del indicador conocimiento del trabajo, en los que se observa cómo los directivos opinan, en un $40 \%$, que siempre el personal está en constante formación para su trabajo, al igual que cuenta con un alto nivel de conocimiento en su trabajo, además de que ha sido entrenado para llevar a la práctica los conocimientos; luego, con un $60 \%$, se encuentran los que consideran que casi siempre, mientras que las opciones algunas veces, casi nunca y nunca no marcaron inclinación de respuestas.
En cuanto a los datos emitidos por los docentes, estos coinciden con los directivos al señalar en un $29 \%$ que siempre estos aspectos se cumplen en la organización. Además, un $25 \%$ plantea que algunas veces se cumplen, seguido de un $22 \%$ con casi siempre, un $18 \%$ que piensa que casi nunca y, por último, se encuentra la alternativa nunca con un $6 \%$.

Los resultados entre directivos y docentes coinciden con Robbins (2008), pues este autor señala que ser competente implica tener la capacidad de ejecución, es decir, el conocimiento procesal o las destrezas intelectuales y psicomotoras para, en efecto, llevar a cabo la ejecución sobre el objeto. 
Finalmente, ser competente implica tener la actitud o el conocimiento actitudinal para querer hacer uso del conocimiento declarativo y procesal, además de actuar de una manera que se considera correcta.

En cuanto al indicador producción, los directivos consideran, en un $40 \%$, que siempre y casi siempre se orienta a lograr las metas sin sacrificar la calidad. De igual modo, considera que emplea más tiempo del previsto para que el resultado sea excelente, además de que es un directivo productivo. Luego, un $40 \%$ considera que casi siempre, y un $20 \%$ de los que señalan que algunas veces sucede. Las opciones casi nunca y nunca no tuvieron inclinación de respuestas.

De esta manera, los docentes coinciden en un $30 \%$ con los directivos al señalar que casi siempre estos aspectos se cumplen. Además, un $27 \%$ plantea que siempre lo hace, seguido de un $24 \%$ que señala algunas veces, un $14 \%$ casi nunca y, por último, la alternativa nunca con un $5 \%$ de respuestas.

Chiavenato (2007) afirma que la cantidad de trabajo que el empleado es capaz de realizar en un tiempo determinando determina el nivel de compromiso y las capacidades de administración del tiempo. La calidad de trabajo se refiere al esmero con el que un empleado realiza su trabajo. Una gestión eficaz de los recursos humanos es, pues, indisociable con la calidad laboral.

Los resultados coinciden con Koontz y Weirich (2007), ya que estos autores afirman que la calidad laboral afecta de manera positiva la rentabilidad de las organizaciones, por lo que es necesario apostar por la introducción de dichas medidas en la gestión empresarial. La calidad del trabajo, en cualquier empresa, se sustenta en la capacidad de mantener en operación de manera estable sus sistemas. Además, a fin de lograrlo se necesita contar con personas motivadas y capacitadas para desarrollar un buen trabajo. Cuando las personas actúan de forma consistente y están dispuestas a superarse constantemente, sumados los recursos necesarios, se puede ser competitivo en cualquier ámbito.
En los resultados del indicador responsabilidad se observa que los directivos opinan, en un $60 \%$, que siempre cumple con las responsabilidades asignadas al cargo y, aunado a esto, valoran el cumplimiento del trabajo en el desempeño laboral. Luego, con un $40 \%$ se encuentran los que consideran que casi siempre sucede; las alternativas algunas veces, casi nunca y nunca no obtuvieron inclinación de respuestas.

Se aprecia que los docentes difieren de los directivos al señalar, en un $28 \%$, que algunas veces el directivo cumple estos aspectos. Además, un $25 \%$ plantea que casi siempre los tiene, seguido de un $23 \%$ con siempre, un $13 \%$ piensa que nunca y, por último, un $11 \%$ están con la alternativa casi nunca.

Conviene subrayar el planteamiento de Chiavenato (2007), quien afirma que la responsabilidad se consolida cuando en un colectivo los trabajadores y los dirigentes se relacionan de forma constante, analizan los problemas desde todos los ángulos a fin de concebir el proceso de trabajo como algo social y personal, a fin de fomentar la responsabilidad por las acciones en la empresa. Sobre esta base se establece que la responsabilidad de las empresas implica -en especial las que prestan servicio público, como lo es el Banco Central de Venezuela, subsede Maracaibo - una seria consideración del pacto de sus acciones en la sociedad. De igual forma, la sensibilidad del establecimiento de una relación entre las operaciones y su política.

En este orden de ideas, Maristany (2003) destaca la medida en que asume la responsabilidad de su puesto. La responsabilidad ante el trabajo es la respuesta positiva ante la obligación contraída, actitud que se asume ante los resultados de la labor. Esto implica que sabe responder ante los demás por una actividad encomendada.

En los resultados del indicador capacidad de liderazgo se observa cómo los directivos opinan, en un $60 \%$, que siempre el personal del instituto ha sido formado en las competencias de liderazgo. Aunado a esto, el personal de supervisión conduce al personal hacia las metas establecidas, así como asume la iniciativa para ejercer labores de 
liderazgo en caso necesario. Luego, con un $40 \%$, se encuentran los que consideran que casi siempre; las alternativas algunas veces, casi nunca y nunca no obtuvieron inclinación de respuestas.

Se observa que los docentes difieren de los directivos al señalar, con el $40 \%$, que algunas veces estos aspectos se cumplen en la institución. Además, un $29 \%$ plantea que casi siempre los tienen, seguido de un $15 \%$ de casi nunca, un $13 \%$ piensa que siempre y, por último, un $3 \%$ opina que nunca.

El planteamiento de Ginebra (2008) coincide con los resultados cuando expresa que el liderazgo se relaciona con la conducción, la dirección y el mando, de manera que representa más una responsabilidad que un rango de privilegio en las organizaciones. De acuerdo con los planteamientos de estos autores, se establece una potencialidad liberadora, lo que convierte al líder en el servidor de sus seguidores en cuanto asume la misión fundamental de ayudarlos a superar los obstáculos para que sean capaces de poner en acción su total capacidad al servicio. De acuerdo con Chiavenato (2007, p. 406), ese tipo de liderazgo «posee autenticidad, el líder es aquella persona capaz de provocar la liberación, desde dentro de la energía interior de otros seres humanos que se han propuesto para lograr su propia dignificación y la de aquellos con quienes conviven».
Para el indicador identidad laboral, los directivos consideran en un $40 \%$ que siempre demuestra identificación con las actividades asignadas, así como promueve la identificación de los trabajadores con la institución. Aunado a lo anterior, se identifica con los objetivos organizacionales, luego un $20 \%$ considera que casi siempre, algunas veces y nunca. La opción casi nunca no tuvo inclinación de respuestas.

De esta manera, los docentes difieren de los directivos en un $40 \%$ al señalar que algunas veces estos aspectos se cumplen. Además, un $23 \%$ plantea que casi siempre lo hace, seguido de un $15 \%$ de casi nunca, un $13 \%$ de siempre y, por último, la alternativa nunca con un $3 \%$ de respuestas.

Ahora bien, Koontz y Weirich (2007) postulan que la identidad organizacional define el grado en el cual el trabajador se siente identificado con las metas y los objetivos trazados por la organización y en función de ello orienta su comportamiento al logro de estos, ejecutando una labor eficiente y eficaz en sus actividades de trabajo.

De igual forma, Chiavenato (2007) sostiene que la identidad laboral se expresa en la medida en que el trabajador siente reciprocidad con los lineamientos laborales de la organización y se orienta a lograr la misión y la visión, en razón a que se identifica con esta. Dicha identidad lo impulsa a realizar una labor ajustada a los propósitos establecidos y a alcanzar metas de excelencia. 
Tabla 4. Dimensión: niveles del desempeño laboral

\begin{tabular}{|c|c|c|c|c|c|c|c|c|c|c|c|c|c|c|c|c|c|c|c|c|}
\hline Alternativas & \multicolumn{4}{|c|}{ Siempre } & \multicolumn{4}{|c|}{ Casi siempre } & \multicolumn{4}{|c|}{ Algunas veces } & \multicolumn{4}{|c|}{ Casi nunca } & \multicolumn{4}{|c|}{ Nunca } \\
\hline Población & \multicolumn{2}{|c|}{ Dir } & \multicolumn{2}{|c|}{ Doc } & \multicolumn{2}{|c|}{ Dir } & \multicolumn{2}{|c|}{ Doc } & \multicolumn{2}{|c|}{ Dir } & \multicolumn{2}{|c|}{ Doc } & \multicolumn{2}{|c|}{ Dir } & \multicolumn{2}{|c|}{ Doc } & \multicolumn{2}{|c|}{ Dir } & \multicolumn{2}{|c|}{ Doc } \\
\hline $\begin{array}{l}\text { Porcentaje } \\
\text { Indicador }\end{array}$ & $\mathbf{F a}$ & $\%$ & $\mathbf{F a}$ & $\%$ & $\mathbf{F a}$ & $\%$ & $\mathbf{F a}$ & $\%$ & $\mathbf{F a}$ & $\%$ & $\mathbf{F a}$ & $\%$ & $\mathbf{F a}$ & $\%$ & $\mathbf{F a}$ & $\%$ & $\mathbf{F a}$ & $\%$ & $\mathbf{F a}$ & $\%$ \\
\hline Destacado & 3 & 60 & 3 & 4 & 1 & 20 & 17 & 22 & 1 & 20 & 31 & 39 & 0 & 0 & 16 & 20 & 0 & 0 & 12 & 15 \\
\hline Competente & 3 & 60 & 9 & 12 & 1 & 20 & 8 & 10 & 1 & 20 & 34 & 43 & 0 & 0 & 12 & 15 & 0 & 0 & 16 & 20 \\
\hline Básico & 0 & 0 & 11 & 14 & 1 & 20 & 12 & 15 & 2 & 40 & 28 & 35 & 2 & 40 & 11 & 14 & 0 & 0 & 17 & 22 \\
\hline Insatisfactorio & 0 & 0 & 25 & 32 & 0 & 0 & 24 & 30 & 0 & 0 & 15 & 19 & 2 & 40 & 10 & 13 & 3 & 60 & 5 & 6 \\
\hline Resumen & \multicolumn{2}{|c|}{120} & \multicolumn{2}{|c|}{62} & \multicolumn{2}{|c|}{60} & \multicolumn{2}{|c|}{77} & \multicolumn{2}{|c|}{80} & \multicolumn{2}{|c|}{136} & \multicolumn{2}{|c|}{80} & \multicolumn{2}{|c|}{62} & \multicolumn{2}{|c|}{60} & \multicolumn{2}{|c|}{63} \\
\hline Porcentaje & \multicolumn{2}{|c|}{30} & \multicolumn{2}{|c|}{16} & \multicolumn{2}{|c|}{15} & \multicolumn{2}{|c|}{19} & \multicolumn{2}{|c|}{20} & \multicolumn{2}{|c|}{34} & \multicolumn{2}{|c|}{20} & \multicolumn{2}{|c|}{15} & \multicolumn{2}{|c|}{15} & & \\
\hline
\end{tabular}

Nota. ${ }^{*} \mathrm{Fa}=$ Frecuencia absoluta. ${ }^{*}$ Dir $=$ Directivos.Doc $=$ Docentes.

Fuente. Elaboración propia.

Figura 2. Niveles del desempeño laboral.
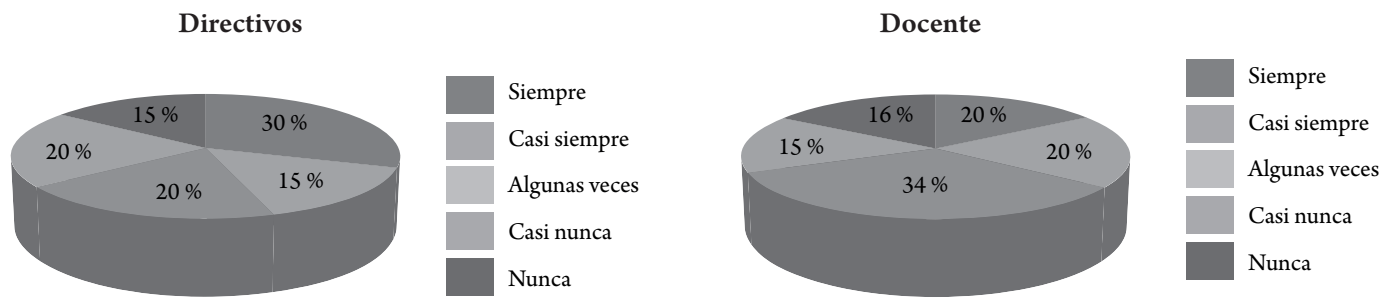

Fuente. Elaboración propia.

Luego del procesamiento de los instrumentos se procede a realizar en la tabla 3 la distribución estadística de los datos de la dimensión nivel del desempeño laboral. En esta tabla se exponen los resultados del indicador destacado, en los cuales se observa que los directivos opinan, en un $60 \%$, que en esta dimensión el trabajador siempre desarrolla la innovación en los puestos de trabajo, al igual que muestra un espíritu de colaboración en las relaciones con los compañeros, aunado a que se destaca por su calidad; luego, con un $20 \%$, se encuentran los que consideran que casi siempre y algunas veces lo hace, mientras que las opciones casi nunca y nunca no marcaron inclinación de respuestas.
En cuanto a los datos emitidos por los docentes, estos difieren de los directivos al señalar en un $39 \%$ que algunas veces estos aspectos se cumplen. Además, un $22 \%$ plantea que casi siempre, seguido de un $20 \%$ con casi nunca, un $15 \%$ piensa que nunca $y$, por último, la alternativa siempre con un $4 \%$.

Resalta el planteamiento de Blanco y Di Vora (2000), quienes señalan que este nivel explica la exigencia de tal manera que presenta esmero en el trabajo y logra así una altísima calidad. Al mismo tiempo manifiesta conocer el trabajo, demostrando experiencia en las funciones de facilitador, orientador, investigador, promotor social, evaluador y planificador. Además, este nivel evidencia un excelente espíritu 
de colaboración en las relaciones interpersonales con los compañeros, así como contribuye a formar y afianzar valores y actitudes mientras desarrolla en cada alumno sus capacidades de aprendizaje relacionadas con el saber, el hacer y el convivir.

Para el indicador competentes los directivos consideran, en un $60 \%$, que siempre demuestra interés en colaborar para lograr las metas. De igual forma, considera que tiene conocimientos suficientes en sus labores, aunado a que mantiene solo las relaciones interpersonales necesarias para ejecutar sus labores. Luego, un $20 \%$ considera que casi siempre y algunas veces lo hace. Las opciones casi nunca y nunca no obtuvieron inclinación de respuestas.

De esta manera, los docentes difieren con un $43 \%$ de los directivos al señalar que algunas veces estos aspectos se cumplen en la organización. Además, un $20 \%$ plantea que nunca, seguido de un $15 \%$ con casi nunca, un $12 \%$ con siempre; por último se encuentra la alternativa casi siempre con un $10 \%$ de respuestas.

Los resultados para los directivos coinciden con Blanco y Di Vora (2000) y difieren de los docentes, ya que en este nivel se demuestra interés en colaborar con el trabajo, así como unas adecuadas relaciones interpersonales, sin llegar a ser excelentes. Es capaz de ejecutar los roles y demostrar moderados conocimientos, con lo cual establece las relaciones interpersonales necesarias.

En los resultados del indicador básico se observa que los directivos opinan, en un $40 \%$, que algunas veces y casi nunca se desenvuelve con los mínimos criterios de calidad. Aunado a esto, maneja un conocimiento básico de las tareas asignadas y solo conoce lo necesario sobre sus tareas. Luego, con un $20 \%$, se encuentran los que consideran que casi siempre; las alternativas siempre y nunca no obtuvieron inclinación de respuestas.
Se observa que los docentes coinciden con los directivos al señalar, en un $35 \%$, que algunas veces se cumplen estos aspectos. Además, un $22 \%$ plantea que nunca, seguido de un $15 \%$ con casi siempre, y un $14 \%$ piensa que siempre y casi nunca sucede.

Los resultados obtenidos de la información proporcionada por el personal directivo y docente difieren con el planteamiento Blanco y Di Vora (2000), ya que en este nivel se demuestra una calidad mínima necesaria y el trabajador conoce solo lo suficiente sobre las tareas o funciones que debe realizar. Demuestra conocimiento básico del contenido de las disciplinas pero no puede hacer conexiones con otros aspectos de la disciplina o relacionarla con la realidad.

En los resultados del indicador insatisfactorio se evidencia que los directivos opinan, en un $60 \%$, que nunca improvisa sus actividades de trabajo. Aunado a esto, jamás las labores se realizan sin planificación y nunca es conformista. Luego, con un $40 \%$, se encuentran los que consideran que casi nunca sucede; por su parte, las alternativas siempre, casi siempre y algunas veces no tuvieron inclinación de respuestas. En cuanto a los docentes difieren de los directivos al señalar, con un $32 \%$, que siempre estos aspectos se cumplen. Además, un $30 \%$ plantea que casi siempre, seguido de un $19 \%$ con algunas veces, el $13 \%$ piensa que casi nunca y, por último, un $6 \%$ señala la alternativa nunca.

Un aspecto clave lo señalan Blanco y Di Vora (2000), pues opinan que en este nivel se presenta una pésima calidad en el trabajo, lo cual demuestra poco conocimiento sobre este, siempre se improvisa, no se planifica ni organiza, tampoco se controla el proceso, además de que no se evalúan las actividades realizadas. De igual forma, estos trabajadores no colaboran con sus compañeros ni con la organización, no presentan capacidad de intuición, demuestran poseer pocas e incluso inadecuadas relaciones interpersonales, no se comunica con su jefe ni con los compañeros y no colaboran en nada. 
Tabla 5. Variable desempeño laboral

\begin{tabular}{|c|c|c|c|c|c|c|c|c|c|c|}
\hline Alternativas & \multicolumn{2}{|c|}{ Siempre } & \multicolumn{2}{|c|}{ Casi siempre } & \multicolumn{2}{|c|}{ Algunas veces } & \multicolumn{2}{|c|}{ Casi nunca } & \multicolumn{2}{|c|}{ Nunca } \\
\hline Población & Dir & Doc & Dir & Doc & Dir & Doc & Dir & Doc & Dir & Doc \\
\hline Porcentaje dimensión & $\%$ & $\%$ & $\%$ & $\%$ & $\%$ & $\%$ & $\%$ & $\%$ & $\%$ & $\%$ \\
\hline Factores del desempeño laboral & 50 & 23 & 45 & 27 & 5 & 29 & 0 & 15 & 0 & 6 \\
\hline $\begin{array}{l}\text { Resumen por alternativa de la } \\
\text { dimensión }\end{array}$ & \multicolumn{2}{|c|}{73} & \multicolumn{2}{|c|}{72} & \multicolumn{2}{|c|}{34} & \multicolumn{2}{|c|}{15} & \multicolumn{2}{|c|}{6} \\
\hline Niveles del desempeño laboral & 30 & 16 & 15 & 19 & 20 & 34 & 20 & 15 & 15 & 16 \\
\hline $\begin{array}{l}\text { Resumen por alternativa de la } \\
\text { dimensión }\end{array}$ & \multicolumn{2}{|c|}{46} & \multicolumn{2}{|c|}{34} & \multicolumn{2}{|c|}{54} & \multicolumn{2}{|c|}{35} & \multicolumn{2}{|c|}{31} \\
\hline Resumen & 80 & 39 & 60 & 46 & 25 & 63 & 20 & 30 & 15 & 22 \\
\hline \multirow{2}{*}{ Resumen general } & \multicolumn{2}{|c|}{119} & \multicolumn{2}{|c|}{106} & \multicolumn{2}{|c|}{88} & \multicolumn{2}{|c|}{50} & \multicolumn{2}{|c|}{37} \\
\hline & \multicolumn{2}{|c|}{30} & \multicolumn{2}{|c|}{26} & \multicolumn{2}{|c|}{22} & \multicolumn{2}{|c|}{13} & \multicolumn{2}{|c|}{9} \\
\hline
\end{tabular}

Nota. ${ }^{*} \mathrm{Fa}=$ Frecuencia absoluta. ${ }^{*}$ Dir $=$ Directivos.Doc $=$ Docentes.

Los porcentajes de cada dimensión se establecen con base en un $200 \%$, ya que incluye el $100 \%$ de directivos y el $100 \%$ de docentes.

Fuente. Elaboración propia, 2018.

Figura 3. Desempeño laboral

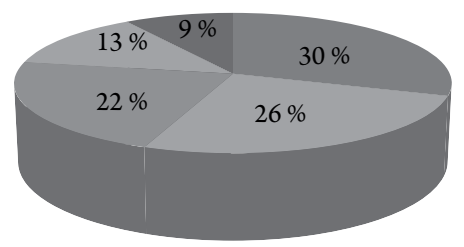

Siempre

Casi siempre

Algunas veces

Casi nunca

Nunca

Fuente. Elaboración propia.

La tabla 5 presenta el estudio de la variable desempeño laboral en sus dimensiones factores del desempeño laboral y los niveles del desempeño laboral. Estos señalan, en general, que el $30 \%$ de los encuestados consideran que siempre esta variable se cumple, seguido de un $26 \%$ que señala que casi siempre, mientras un $22 \%$ cree que algunas veces, un $13 \%$ casi nunca y un $9 \%$ opina que nunca.

Para la dimensión factores del desempeño laboral tenemos, en general, que el $73 \%$ de los encuestados estudiados considera que siempre esta dimensión se cumple, seguido de un $72 \%$ que señala que casi siempre se cumple la dimensión, mientras que un $34 \%$ cree que algunas veces, un $15 \%$ casi nunca y un $6 \%$ opinan que nunca se desempeña efectivamente la dimensión.
En relación con la dimensión niveles del desempeño laboral, tenemos, en general, que el $54 \%$ de los encuestados consideran que solo algunas veces esta dimisión se cumple, seguido de un $46 \%$ que señala siempre se cumple, mientras que un $35 \%$ cree que casi nunca, un $34 \%$ casi siempre y un $31 \%$ opina que nunca se desempeña efectivamente la dimensión.

Es preciso insistir en la definición de desempeño laboral proporcionada por Matas (2006), al que se refiere como la efectividad de acuerdo con criterios sistémicos, por lo cual se mide en función de la capacidad de la administración para adaptarse, mantenerse y crecer, así como de renovarse constantemente o, mejor aún, convertirse en una organización que aprende e incide en los fenómenos de supervivencia, adaptación y crecimiento. 
Tabla 6. Resultados de la variable

\begin{tabular}{|c|c|c|c|c|c|c|c|c|c|c|}
\hline Alternativas & \multicolumn{2}{|c|}{ Siempre } & \multicolumn{2}{|c|}{ Casi siempre } & Algunas veces & \multicolumn{2}{c|}{ Casi nunca } & \multicolumn{3}{c|}{ Nunca } \\
\hline Población & Dir & Doc & Dir & Doc & Dir & Doc & Dir & Doc & Dir & Doc \\
\hline Variable & 80 & 39 & 60 & 46 & 25 & 63 & 20 & 30 & 15 & 22 \\
\hline Resumen & 30 & & 26 & & 22 & & 13 & & 9 & \\
\hline Resumen & $\mathbf{1 1 8}$ & $\mathbf{6 7}$ & $\mathbf{1 0 8}$ & $\mathbf{8 1}$ & $\mathbf{9 2}$ & $\mathbf{1 1 8}$ & $\mathbf{3 7}$ & $\mathbf{7 9}$ & $\mathbf{4 5}$ & $\mathbf{5 5}$ \\
\hline
\end{tabular}

Nota. ${ }^{*} \mathrm{Fa}=$ Frecuencia absoluta. ${ }^{*}$ Dir $=$ Directivos. Doc $=$ Docentes.

Fuente. Elaboración propia, 2018.

En relación con la variable desempeño laboral tenemos, en general, que el $30 \%$ de los encuestados considera que solo algunas veces esta variable se cumple, seguido de un $26 \%$ que señala que siempre se cumple, mientras un $22 \%$ cree que casi nunca, un $13 \%$ casi nunca y un $9 \%$ opina que nunca se desempeña efectivamente la variable.

Con el transcurrir del tiempo las organizaciones le han otorgado mayor importancia a los procesos que realiza el área de talento humano, ya que se han concientizado de la importancia que tienen las personas dentro de las organizaciones y el impacto que estas pueden causar en su competitividad, ya que, precisamente, son los colaboradores de la empresa los que con sus conocimientos y experiencias aportan todo el talento que requieren las organizaciones para alcanzar sus objetivos y metas, de modo que se adaptan a los rápidos cambios que día a día se presentan en el entorno empresarial (Figueroa, 2014; Pardo y Díaz, 2014; Rodríguez y Murillo, 2016).

En primer lugar, al motivar al personal a que consiga los objetivos de la empresa, es decir, a que realicen las «cosas correctas», fortalece la pertenencia a la empresa, mejora el compromiso del empleado, consigue un ahorro de costes derivados del absentismo, el mantenimiento y la retención de personal, las bajas laborales y mejora la productividad (García, Londoño y Ortiz, 2016; Sanín y Salanova, 2014).
En segundo lugar, la clave de éxito de una empresa está en el lugar que se les dé a los empleados. Estos deben percibirse como aliados y parte esencial de toda la empresa. Debe existir una relación ganar-ganar que conduzca a la prestación de un servicio eficiente, y a niveles óptimos de productividad que redunden en mayor competitividad para la empresa (Restrepo y Arias, 2015).

En tercer lugar, una gestión eficiente del desempeño de los empleados le permite a la empresa tener un empleado satisfecho, lo que finalmente beneficia la productividad de este, la orientación al servicio al cliente y un buen clima laboral: $\ll$ Se trata de analizar $y$ cuantificar el valor de individuo para la organización, en relación exclusivamente con su puesto de trabajo y en relación con el periodo evaluado» (Gan y Triginé, 2012, p. 194). Si se cuenta con empleados satisfechos, estos van a dar lo mejor de sí y a tener una actitud positiva frente a la orientación al cliente, lo que impacta en la imagen del servicio que da la compañía como un todo y por lo tanto en su competitividad (Chiang-Vega y San Martín-Neira, 2015).

Finalmente, retener «los buenos empleados» servirá para que la empresa no pierda su mejor capital humano y motivar a los empleados; la retribución puede contribuir a la motivación del individuo al vincular las recompensa al rendimiento (Editorial Vértice, 2008, p. 6). 


\section{Conclusiones}

$\mathrm{A}$ partir de los apartados anteriores se ha logrado comprender cuál es el estado actual del desempeño laboral de docentes y directivos docentes en la Institución Universitaria ITSA, y, a partir de las opiniones de los encuestados, cuál es la situación con respecto a los factores del desempeño laboral y los niveles del desempeño laboral. En definitiva, sobre la base de los resultados obtenidos con la realización de las encuestas se pueden enumerar algunas conclusiones generales.

En relación con la dimensión factores del desempeño laboral se puede concluir que factores tales como conocimiento del trabajo, producción, responsabilidad, capacidad de liderazgo e identidad laboral son para los directivos de uso frecuente en la práctica educativa en la Institución Universitaria ITSA. A pesar de que los docentes declaran una frecuencia regular con respecto a estos factores, se observa que debería aumentar su aplicación en la experiencia docente de los maestros encuestados.

Con respecto al nivel de desempeño laboral, los directivos se identifican con niveles destacados y competentes. Estos desempeños son regulares en contrate con los docentes con frecuencia media, quienes se encuentran identificados con las categorías de desempeño competente y básico, lo que denota la necesidad de una mayor motivación para aumentar niveles de desempeño más alto en los docentes.

En cuanto a la variable desempeño laboral se encuentra que el cumplimiento de factores y niveles es siempre y casi siempre el deseado, en general, tanto para directivos como para docentes. Esto sugiere mantener el desempeño y mejorar en los factores de desempeño analizados, así como en la motivación de los docentes, a fin de aumentar sus niveles de desempeño.

Finalmente, podemos afirmar que la presente investigación sirve como paso previo para futuras líneas de investigación que incluyan una investigación empírica encaminada a profundizar en el conocimiento del desempeño laboral en la Institución Universitaria ITSA. Con miras en esto se considera oportuno dar continuidad a este estudio planteando como futuras líneas de trabajo el desarrollo de una investigación empírica que incluya la variable comunicación organizacional, la cual pueda facilitar datos cuantitativos y estadísticamente relevantes. 


\section{Referencias}

Bascón, M.; Cazallo, A.; Lechuga, J.; Meñaca, I. (2016). Estudio de la necesidad de implantar un servicio público de transporte entre las ciudades de Ceuta-Tetuán y MelillaNador. Desarrollo Gerencial, 8(2), 37-57. DOI: https://doi. org $/ 10.17081 /$ dege.8.2.2553

Bavaresco de Prieto, A. M. (2013). Proceso metodológico de la investigación. Maracaibo, Venezuela: Imprenta internacional.

Blanco, E.; Di Vora, M. (2000). Evaluación del personal. Caracas: Ediciones Publicitarias.

Chávez, N. (2007). Introducción a la investigación educativa. Maracaibo: Gráfica González.

Chiavenato, I. (2007). Administración de recursos humanos. El capital humano en las organizaciones. México: Editorial McGraw Hill.

Chiang-Vega, M. M.; San Martín-Neira, N. J. (2015). Análisis de la satisfacción y el desempeño laboral en los funcionarios de la Municipalidad de Talcahuano. Ciencia \& Trabajo, 17(54), 159-165. DOI: https://doi.org/10.4067/ $\underline{\text { S0718-24492015000300001 }}$

Dessler, G. (2007). Administración de recursos humanos. México: Pearson.

Díaz, M. (2005). La comunicación interna de la empresa. Gestiopolis.

Editorial Vértice. (2008). Dirección de recursos humanos. Málaga: Vértice.

Figueroa, H. (2014). Estrategias de atracción y retención del talento humano en la industria minera colombiana, Revista Económicas CUC, 35(1), 61-77. Recuperado de https:// revistascientificas.cuc.edu.co/economicascuc/article/ view/219

Gan, F.; Triginé, J. (2012). Evaluación del desempeño individual. España: Díaz de Santos.

García, D.; Londoño, C.; Ortíz, L. (2016). Factores internos y externos que inciden en la motivación laboral. Revista Psyconex, 8(12), 1-9. Recuperado de https:// aprendeenlinea.udea.edu.co/revistas/index.php/Psyconex/ article/view/326981

Ginebra, J. (2008). El liderazgo y la acción. Mitos y realidades. México D. F.: Editorial McGraw-Hill.

Hernández, R.; Fernández, C.; Baptista, P. (2014). Metodología de la investigación. México: McGraw-Hill.

Koontz, O.; Weirich, H. (2007). Elementos de la administración. México D.F.: Editorial McGraw-Hill.

Kotter, J. (2005). Lo que de verdad hacen los líderes. Harvard Business Review, 83(11), 132-140. Recuperado de https:// educatic2011.files.wordpress.com/2010/10/kotter-2005. pdf

Lechuga, J.; Cazallo, A., Meñaca, I.; Martínez, H.; García, J. Olivero, E.; García, J. (2018). Análisis del comportamiento de las exportaciones del departamento del Atlántico
(Colombia) entre 2012-2016. Revista Espacios, 39(22), 2-20. Recuperado de https://www.revistaespacios.com/ a18v39n22/a18v39n22p22.pdf

Maristany, J. (2003). Administración de recursos humanos. Buenos Aires: Pearson Education.

Matas, D. (2006). Mejorando el desempeño laboral de los trabajadores. España: Pearson Editores.

Morales, J.; Velandia, N. (1999). Salarios estrategia y sistema salarial o de compensaciones. Bogotá: McGraw Hill.

Newstrom, J. (2007). Comportamiento humano en el trabajo. México: McGrawHill.

Pardo, C.; Díaz, O. (2014). Desarrollo del talento humano como factor clave para el desarrollo organizacional, una visión desde los líderes de gestión humana en empresas de Bogotá D.C. Suma de Negocios, 5(11), 39-48. DOI: https:// doi.org/10.1016/S2215-910X(14)70018-7

Restrepo, F.; Arias, F. (2015). Las prácticas de gestión del talento humano en empresas agropecuarias del sector bananero en Colombia. Journal of Agriculture and Animal Sciences, 4(2), 20-32. Recuperado de http://repository.lasallista.edu. co:8080/ojs/index.php/jals/article/view/912/635

Robbins, S.; Coulter, M. (2005). Administración ( $8^{\mathrm{a}}$ ed.) México: Editorial Pearson.

Robbins, S. (2008). Comportamiento organizacional. México D. F.: Editorial Prentice Hall.

Rodríguez, M.; Murillo, S. (2016). Talento humano en la microempresa informal. Dominio de las Ciencias, 2, 247-256. Recuperado de https://dialnet.unirioja.es/servlet/ articulo? codigo $=5761577$.

Sanín, J. A.; Salanova, M. (2014). Satisfacción laboral: el camino entre el crecimiento psicológico y el desempeño laboral en empresas colombianas industriales y de servicios. Universitas Psychologica, 13(1). DOI: https://doi.org/10.11144/ Javeriana.UPSY13-1.slcp

Tamayo; y Tamayo, M. (2009). El proceso de investigación científica. México: Limusa.

Tobón, S. (2004). Formación Integral y Competencias. Bogotá: Ecoe Ediciones.

Toro, F. y Cabrera, H. (1985). Motivación para el trabajo. Conceptos, hechos y evidencias contemporáneos. Medellín: Cincel. 
